\title{
Phosphodiesterase type 4 inhibitor rolipram inhibits activation of monocytes during extracorporeal circulation
}

\author{
Yukio Sato, MD, PhD, ${ }^{\text {a }}$ Yuji Hiramatsu, MD, PhD, ${ }^{\mathrm{c}}$ Satoshi Homma, MD, PhD, ${ }^{\mathrm{c}}$ Makiko Sato, MD, ${ }^{\mathrm{b}}$ Shyoko Sato, \\ Shunsuke Endo, MD, PhD, and Yasunori Sohara, MD, $\mathrm{PhD}^{\mathrm{a}}$
}

Objective: Cardiopulmonary bypass is associated with systemic inflammatory response syndrome and risk of multiorgan injury mediated by activated leukocytes. Phosphodiesterase type 4 is the predominant phosphodiesterase isozyme in leukocytes and plays a key role in the regulation of leukocyte activation. The aim of this study was to examine the effect of rolipram, a selective phosphodiesterase type 4 inhibitor, on functional changes of monocytes during simulated extracorporeal circulation.

Methods and Results: Simulated extracorporeal circulation was established by recirculating heparinized human blood for 120 minutes on a membrane oxygenator with or without $10 \mu \mathrm{mol} / \mathrm{L}$ of rolipram. L-selectin and CD11b expression of monocytes were measured with flow cytometry. C4d fragment, Bb fragment, C5b-9, and interleukin- 6 were measured with enzyme immunoassay. Rolipram reduced the increase in CD11b expression and the decrease in L-selectin expression of monocytes in response to simulated extracorporeal circulation. Rolipram inhibited the increase in $\mathrm{C} 4 \mathrm{~d}$ fragment and interleukin-6, but it did not affect the increase in $\mathrm{Bb}$ fragment or C5b-9.

Conclusion: Rolipram inhibited changes in adhesion molecule expression and interleukin- 6 release by activated monocytes in simulated extracorporeal circulation. This study suggests that phosphodiesterase type 4 inhibition could be feasible therapeutic strategy to prevent exaggerated inflammatory response and organ injury in patients undergoing cardiopulmonary bypass.

From the Division of Thoracic Surgery, De-

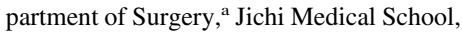
Minamikawachi, Tochigi, Japan, and Department of Medicine, ${ }^{\text {b Jichi Medical }}$ School, University of Tsukuba, ${ }^{\mathrm{c}}$ Institute of Clinical Medicine, Tsukuba, Ibaraki, Japan.

This work was supported by a grant-in-aid for scientific research of Japan (C) (2) 15591488.

Received for publication Sept 30, 2004; revisions accepted Dec 18, 2004; accepted for publication Dec 23, 2004.

Address for reprints: Yukio Sato, MD, $\mathrm{PhD}$, Division of Thoracic Surgery, Department of Surgery, Jichi Medical School, 3311-1 Minamikawachi, Kawachi, Tochigi 329-0498, Japan (E-mail: tcvysato@ jichi.ac.jp).

J Thorac Cardiovasc Surg 2005;130:346-50

$0022-5223 / \$ 30.00$

Copyright () 2005 by The American Association for Thoracic Surgery

doi:10.1016/j.jtcvs.2004.12.028
$\mathrm{C}$ ardiopulmonary bypass (CPB) is associated with systemic inflammatory response syndrome, in which patients are at risk for organ injury typical of acute respiratory distress syndrome. It is well documented that this injury is mediated by activated polymorphonuclear (PMN) leukocytes and monocytes. ${ }^{1-3}$ Monocytes are activated by both the direct contact with the synthetic surface and the activated complements produced during CPB. ${ }^{1,2,4,5}$ Monocytes produce numerous proinflammatory and anti-inflammatory cytokines including interleukins (ILs)-1, 2, $4,6,8,10$, and 12. Monocyte expression of CD11b increases to peak 24 hours after $\mathrm{CPB}^{2}$

We previously documented that a phosphodiesterase (PDE) type 4 inhibitor inhibits the activation of PMN in a simulated extracorporeal circulation (SECC) model. ${ }^{6}$ cAMP is an intracellular messenger that has a suppressant effect on leukocyte activation. ${ }^{7}$ cAMP is inactivated by PDE, and PDE type 4 is the predominant PDE isozyme in leukocytes. ${ }^{7}$ Specific PDE type 4 inhibitors increase cAMP in leukocytes and are reported to inhibit increase of cytosolic calcium in stimulated human leukocytes, ${ }^{8}$ a pivotal event in leukocyte activation. ${ }^{9}$ Therefore, inhibition of PDE type 4 in SECC is considered to inhibit the activation of leukocytes through cAMP. Furthermore, it is speculated that PDE type 4 inhibition inhibits monocyte 
activation in SECC because cAMP also has a suppressant effect on monocyte activation. ${ }^{7,10}$

Our working hypothesis is that PDE type 4 inhibitor inhibits monocyte activation during $\mathrm{CPB}$, which could lead to reduction of the systemic inflammatory response and prevention of organ injury related to $\mathrm{CPB}$. We and others used SECC extensively as an in vitro model of inflammatory responses during in vivo CPB. ${ }^{6,11,12}$ This study evaluated the effect of the PDE type 4 inhibitor rolipram on monocyte activation during SECC. We evaluated the effect of rolipram on complement activation, expression of adhesion molecules, and release of IL-6 by monocytes.

\section{Methods}

\section{Simulated Extracorporeal Circulation}

The effect of extracorporeal circulation on the activation of leukocytes was evaluated by using SECC as described previously. ${ }^{6,11,13}$ Each perfusion circuit (surface area $0.66 \mathrm{~m}^{2}$ ) was assembled from Silastic tubing (0.25-inch inside diameter; MERA, Tokyo, Japan), polycarbonate connectors, a polyvinyl chloride venous reservoir bag (MERA), and a $0.6 \mathrm{~m}^{2}$ membrane oxygenator (model 60EC; MERA). All components of the circuit were sterilized and used once. Human blood $(250 \mathrm{~mL})$ was drawn from healthy male donors (age 25-40 years) through an 18-gauge needle and polyvinyl tubing directly into a venous reservoir bag containing heparin $(3.75 \mathrm{U} / \mathrm{mL})$. Donors abstained from all medications for at least 2 weeks before donation. Written informed consent was obtained from all donors, and the protocol was approved by the institutional review board of the University of Tsukuba.

The perfusion circuit was filled with blood (control group, $\mathrm{n}=$ 6) or blood containing rolipram $(10 \mu \mathrm{mol} / \mathrm{L}$ final concentration, BIOMOL Research Laboratories, Inc, Plymouth Meeting, Pa) (rolipram-treated group, $\mathrm{n}=6$ ). Blood was recirculated with a barely occlusive roller pump (model MS-033; MERA) at 400 $\mathrm{mL} / \mathrm{min}$ for 120 minutes. Oxygenators were ventilated with $95 \%$ oxygen and 5\% carbon dioxide at a rate of $0.7 \mathrm{~L} / \mathrm{min}$. Blood temperature was maintained at $37^{\circ} \mathrm{C}$ by immersing the reservoir bag in a constant-temperature shaking water bath. Four blood samples were drawn from the reservoir into polypropylene tubes before recirculation (time zero) and 30, 60, and 120 minutes after recirculation. The standing control sample ( $3.75 \mathrm{U} / \mathrm{mL}$ heparin) was incubated for 120 minutes in a shaking water bath at $37^{\circ} \mathrm{C}$ before processing. Blood samples for blood cell counts and differential white cell counts were collected in tubes containing potassium ethylene tetra acetic acid (VT-052DK, Venoject; Terumo, Tokyo, Japan). Blood samples for CD11b and L-selectin were collected into tubes containing acid-citrate-dextrose (9:1 by volume). Blood samples for complement and IL-6 analysis were collected and centrifuged at $3000 \mathrm{rpm}$ for 15 minutes, and the supernatant was stored at $80^{\circ} \mathrm{C}$ until measurement.

\section{Blood Cell Counts}

Blood cell counts were performed with a counter (T-660, Coulter Electronics, Hialeah, Fla), and differential white cell counts were performed on Wright's-stained blood smears by an experienced independent observer.

\section{Adhesion Molecule Assays}

Changes in the surface expression of L-selectin and CD11b on monocytes were measured by flow cytometry as described previously. ${ }^{14}$ One-hundred microliters of whole-blood samples were incubated for 30 minutes with $2 \mu \mathrm{g} / \mathrm{mL}$ of fluorescein isothiocyanate-conjugated mouse monoclonal CD62L antibody (isotype IgG1 kappa, Pharmingen, San Diego, Calif) and $1 \mu \mathrm{g} / \mathrm{mL}$ phycoerythrin-conjugated mouse monoclonal antihuman CD11b antibody (isotype IgG1 kappa, DAKO Laboratories, Glostrup, Denmark) antibody or at $4^{\circ} \mathrm{C}$. Identical samples were incubated with fluorescein isothiocyanate-conjugated mouse immunoglobulin (Ig)G (isotype IgG1 kappa, DAKO) and phycoerythrin-conjugated mouse IgG (isotype IgG1 kappa, DAKO) as negative controls. Erythrocytes were lysed for 60 seconds with Immuno-lyse, and leukocytes were fixed with Immuno-fix (Coulter Clone kits, Coulter Immuno, Hialeah, Fla). Monocytes were identified according to the typical forward- and side-scatter pattern, and expression of L-selectin and CD11b was measured simultaneously as the mean fluorescence intensity of 3000 monocytes. Changes in Lselectin and CD11b levels were expressed as percentage changes compared with baseline values.

\section{Serum Assays}

To evaluate complement activation, $\mathrm{C} 4 \mathrm{~d}$ fragment, $\mathrm{Bb}$ fragment, and C5b-9 (the terminal complement component) were measured with enzyme-linked immunosorbent assay kits (Quidel Corporation, San Diego, Calif) according to the manufacturer's instructions. IL-6 was measured with a high-sensitivity enzyme-linked immunosorbent assay kit (AN'ALYZA IL-6 HS; Genzyme Tech, Minneapolis, Minn) according to the manufacturer's instructions.

\section{Statistical Analysis}

One-way analysis of variance compared with time 0 value was used for within-group comparison. Two-way analysis of variance with repeated measure was used for the comparison between groups. The sequential rejective Bonferroni test was used to correct for multiple comparisons. ${ }^{15}$ All values are expressed as the mean \pm standard error.

\section{Results}

\section{Blood Cell Counts}

The white blood cell count and hematocrit did not change significantly in either group (data not shown). The monocyte count did not change significantly in either group (313 $\pm 35 \mu \mathrm{L}$ to $252 \pm 25 \mu \mathrm{L}$ in the control group, $357 \pm 45 \mu \mathrm{L}$ to $319 \pm 40 \mu \mathrm{L}$ in the rolipram group).

\section{Adhesion Molecule Assays}

Typical flow cytometry plots of the control group at 0 and 120 minutes, and the standing control, are shown in Figure 1. L-selectin and CD11b were stained simultaneously on monocytes, and the mean fluorescent intensities were used for the evaluation of changes of adhesion molecules. The expression of L-selectin on monocytes decreased to $28.1 \%$ $\pm 5.2 \%$ of the baseline value at 120 minutes in the control group (Figure 2, A, $P<.0001$ ). Rolipram significantly 

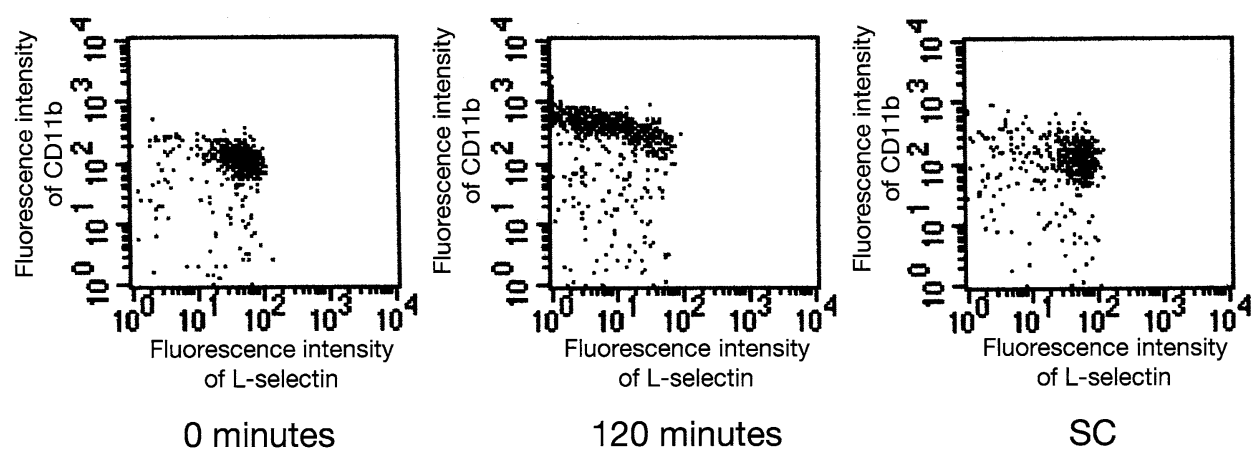

Figure 1. Typical flow cytometry plots of control group at $\mathbf{0}$ and 120 minutes, and standing control (SC). L-selectin and CD11b were stained simultaneously on monocytes, and the mean fluorescent intensities were used for the evaluation of changes of adhesion molecules.

attenuated this decrease $(P<.05,45.8 \% \pm 3.7 \%$ of the baseline value at 120 minutes). The expression of CD11b on monocytes increased to $301.7 \% \pm 27.7 \%$ of the baseline value at 120 minutes in the control group (Figure 2, $B, P<$ $.0001)$. Rolipram significantly inhibited this increase $(P<$ $.05,188.2 \% \pm 29.5 \%$ of the baseline value at 120 minutes). Rolipram inhibited the change in adhesive quality of monocytes induced by SECC.

\section{Serum Assays}

C4d fragment, an indicator of the classic complement pathway, ${ }^{16}$ increased from $0.32 \pm 0.08 \mu \mathrm{g} / \mathrm{mL}$ to $0.72 \pm 0.11$ $\mu \mathrm{g} / \mathrm{mL}$ at 120 minutes in the control group (Figure 3, A, $P<.05)$. Rolipram significantly inhibited this increase $(P<.01,0.26 \pm 0.04 \mu \mathrm{g} / \mathrm{mL}$ at 120 minutes $)$. Bb fragment, an indicator of the alternative complement pathway, ${ }^{17}$ increased at 120 minutes in both the control group (Figure 3, $B, P<.05,0.04 \pm 0.01 \mu \mathrm{g} / \mathrm{mL}$ to $0.26 \pm 0.04 \mu \mathrm{g} / \mathrm{mL})$ and the rolipram-treated group $(P<.05,0.04 \pm 0.01 \mu \mathrm{g} / \mathrm{mL}$ to $0.25 \pm 0.02 \mu \mathrm{g} / \mathrm{mL}$ ). Rolipram did not alter this increase in $\mathrm{Bb}$ fragment. C5b-9, a terminal complement complex that mediates irreversible membrane damage of target cells ${ }^{18}$ increased at 120 minutes in both the control group (Figure $3, C, P<.001,121.2 \pm 42.1 \mu \mathrm{g} / \mathrm{mL}$ to $1190.5 \pm 149.4$ $\mu \mathrm{g} / \mathrm{mL})$ and the rolipram-treated group $(P<.005,73.7 \pm$ $4.4 \mu \mathrm{g} / \mathrm{mL}$ to $1259.7 \pm 254.8 \mu \mathrm{g} / \mathrm{mL}$ ). Rolipram did not alter this increase in C5b-9. IL-6, an inflammatory cytokine released predominantly from monocytes, increased from $0.96 \pm 0.26 \mu \mathrm{g} / \mathrm{mL}$ to $7.80 \pm 0.95 \mu \mathrm{g} / \mathrm{mL}$ at 120 minutes in the control group (Figure $4, P<.0001$ ). Rolipram significantly inhibited this increase $(P<.001,1.25 \pm 0.44$ $\mu \mathrm{g} / \mathrm{mL}$ at 120 minutes).

\section{Discussion}

Systemic inflammatory response syndrome is a major cause of complication of $\mathrm{CPB}$, and activated monocytes play an
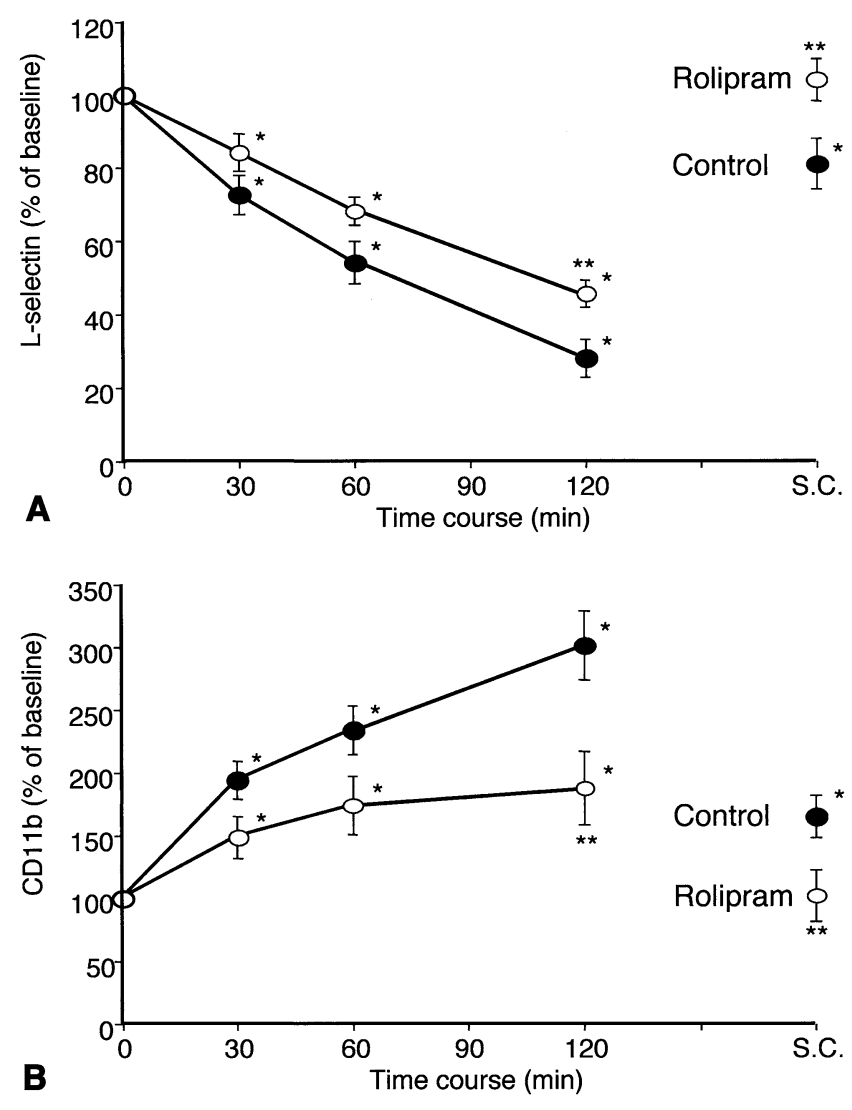

Figure 2. Expression of L-selectin and CD11b on monocytes. A, Expression of L-selectin on monocytes decreased in both control and rolipram-treated groups. Rolipram attenuated this decrease. Results are expressed as mean \pm standard error of mean (SEM) of 6 experiments. ${ }^{*} P<.0001$ versus baseline. ${ }^{* *} P<.05$ versus control. B, Expression of CD11b on monocytes increased in both control and rolipram-treated groups. Rolipram inhibited this increase. Results are expressed as mean \pm SEM of 6 experiments. ${ }^{*} \boldsymbol{P}<.0001$ versus baseline. ${ }^{* *} \boldsymbol{P}<.05$ versus control. 


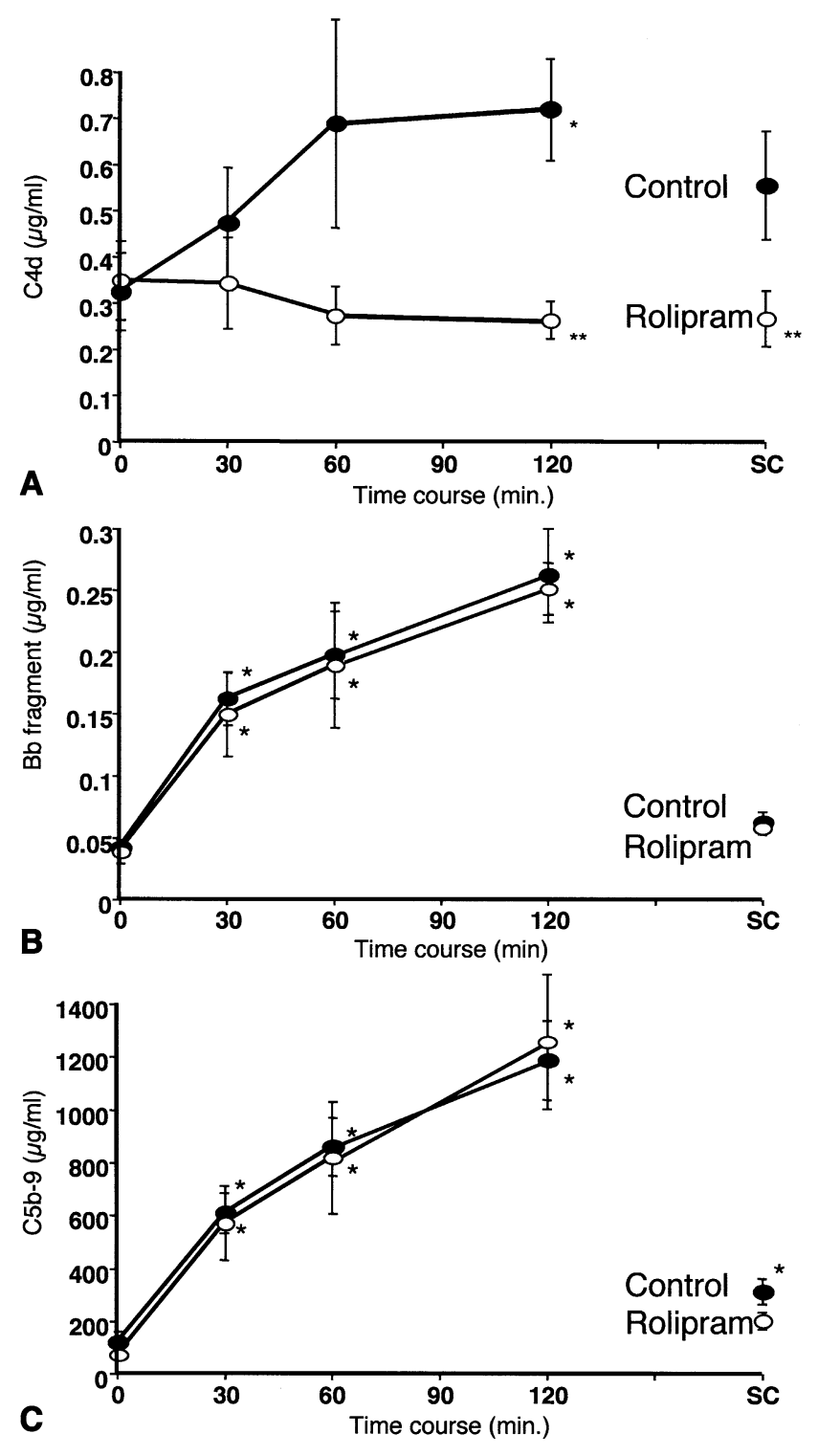

Figure 3. C4d fragment, Bb fragment, and C5b-9 concentrations. A, C4d fragment, an indicator of the classic complement pathway, increased in the control group. Rolipram inhibited this increase. Results are expressed as mean \pm SEM of 6 experiments. ${ }^{*} P<.05$ versus baseline. ${ }^{* *} P<.01$ versus control. $B, B b$ fragment, an indicator of the alternative complement pathway, increased in both control and rolipram-treated groups. Rolipram did not alter this increase. Results are expressed as mean \pm SEM of 6 experiments. ${ }^{*} \boldsymbol{P}<.05$ versus baseline. $C$, C5b-9, a terminal complement complex, increased in both control and rolipram-treated groups. Rolipram did not alter this increase. Results are expressed as mean \pm SEM of 6 experiments. ${ }^{*} P<.005$ versus baseline.

important role in this response associated with $\mathrm{CPB} .{ }^{1-3}$ Monocytes are activated by direct contact with synthetic surface, activated complement, and heat shock proteins pro-

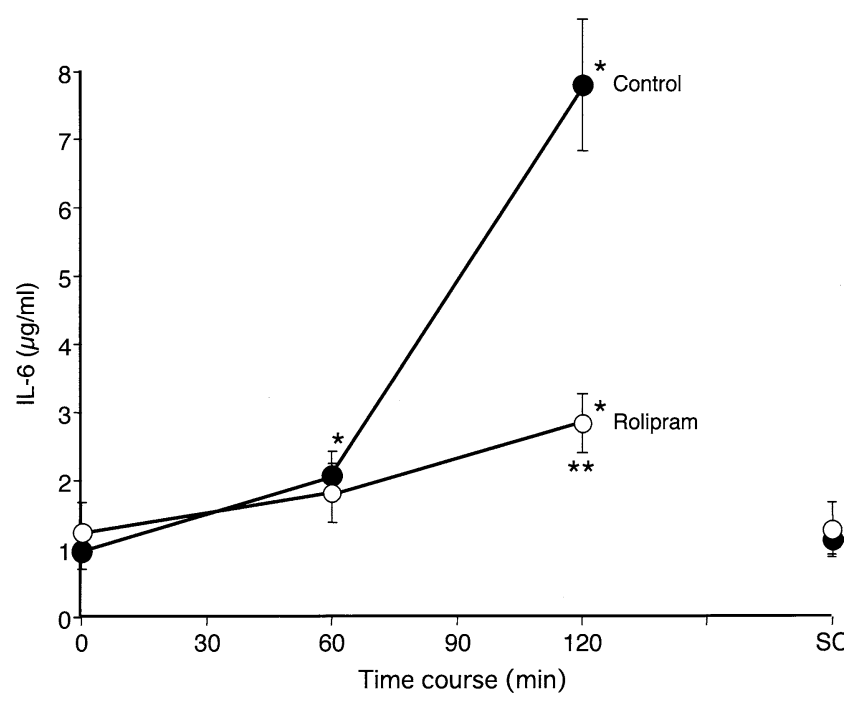

Figure 4. IL-6 concentration. IL-6 increased in both control and rolipram-treated groups. Rolipram inhibited this increase. Results are expressed as mean \pm SEM of 6 experiments. ${ }^{*} P<.0001$ versus baseline, ${ }^{* *} P<.001$ versus control. IL, Interleukin.

duced during CPB. ${ }^{1,2,4}$ Our results show that a selective PDE type 4 inhibitor rolipram inhibits the activation of monocytes induced by SECC. This was associated with inhibitions of the decrease in L-selectin expression, the increase in CD11b expression, and the release of IL- 6 from monocytes. These phenotypic and functional characteristics of monocytes have all been shown to affect leukocytemediated organ injury. ${ }^{19,20}$

SECC decreased L-selectin expression on monocytes (Figure 2, A). This is consistent with observations of PMN in former SECC studies. ${ }^{6}$ SECC increased the expression of CD11b on monocytes (Figure 2, B), which is consistent with previous SECC studies $^{21-23}$ and most clinical studies. ${ }^{3,24}$

$\mathrm{CPB}$ induces complement activation through both the classic and alternative pathways. ${ }^{2,25}$ Activated complement components are major contributors to monocyte activation induced during SECC. ${ }^{12,21}$ SECC induced complement activation of both the classic and alternative pathways, as shown by the increase in $\mathrm{C} 4 \mathrm{~d}$ fragment (Figure $3, A$ ) and $\mathrm{Bb}$ fragment (Figure 3,B), respectively. Rolipram inhibited the increase in $\mathrm{C} 4 \mathrm{~d}$ fragment but did not alter the increase in $\mathrm{Bb}$ fragment. It is not clear from our data why rolipram inhibited activation of the classic pathway. C1q, the initial component of the classic complement pathway, interacts with several immunologically important cell types, including lymphocytes, monocytes, and PMN. ${ }^{26}$ PDE type 4 inhibitors inhibit the functions not only of $\mathrm{PMN}^{6,27}$ but also of monocytes ${ }^{10}$ and lymphocytes. ${ }^{28,29}$ Inhibition of the activation of these leukocytes by rolipram may have resulted in inhibition of the interaction with C1q and activation of the 
classic pathway. SECC increased C5b-9, the terminal complement component, and rolipram did not alter this increase (Figure 3,C). Although rolipram inhibited activation of the classic pathway, it failed to inhibit activation of alternative pathway and the terminal complement component.

SECC induced the release of IL-6 from monocytes (Figure 4), and rolipram inhibited this release. CPB induces an inflammatory response and the release of inflammatory cytokines. ${ }^{2}$ In blood cells, monocytes are the predominant source of cytokines and are known to release numerous inflammatory cytokines in response to $\mathrm{CPB} .{ }^{2}$ The release of these cytokines from monocytes could cause activation of PMN and endothelial cells, resulting in tissue injury. ${ }^{25}$ Our results suggest that rolipram inhibits organ injury by inhibiting monocytes activation and cytokine production. However, in clinical application of PDE type 4 inhibitor, it is possible that PDE type 4 inhibitors cause peripheral vasodilation and hypotension, because PDE type 4 inhibitors also distribute in smooth muscle cells.

In summary, this study showed that the selective PDE type 4 inhibitor rolipram inhibits functional changes of monocytes in an SECC model that mimics inflammatory responses to CPB. Rolipram also inhibits IL-6 release from monocytes, which may enhance inflammatory response. Thus, PDE 4 inhibition is a potential therapeutic strategy for the prevention of exaggerated inflammatory response and organ injury related to $\mathrm{CPB}$.

\section{References}

1. Johnson D, Thomson D, Hurst T, Prasad K, Wilson T, Murphy F, et al. Neutrophil-mediated acute lung injury after extracorporeal perfusion. J Thorac Cardiovasc Surg. 1994;107:1193-202.

2. Edmunds LH Jr. Inflammatory response to cardiopulmonary bypass. Ann Thorac Surg. 1998;66(5 Suppl):S12-6; discussion S25-8.

3. Rinder CS, Bonan JL, Rinder HM, Mathew J, Hines R, Smith BR. Cardiopulmonary bypass induces leukocyte-platelet adhesion. Blood. 1992;79:1201-5.

4. Haeffner-Cavaillon N, Cavaillon JM, Laude M, Kazatchkine MD. $\mathrm{C} 3 \mathrm{a}(\mathrm{C} 3 \mathrm{ades} \mathrm{Arg})$ induces production and release of interleukin 1 by cultured human monocytes. J Immunol. 1987;139:794-9.

5. Dybdahl B, Wahba A, Lien E, Flo TH, Waage A, Qureshi N, et al. Inflammatory response after open heart surgery: release of heat-shock protein 70 and signaling through toll-like receptor-4 [see comment]. Circulation. 2002;105:685-90.

6. Sato Y, Hiramatsu Y, Homma S, Sato S, Onizuka M, Sakakibara Y. Phosphodiesterase type 4 inhibition of activated polymorphonuclear leukocytes in a simulated extracorporeal circulation model. $J$ Thorac Cardiovasc Surg. 2003;125:172-7.

7. Torphy TJ. Phosphodiesterase isozymes: molecular targets for novel antiasthma agents. Am J Respir Crit Care Med. 1998;157:351-70.

8. Anderson R, Goolam Mahomed A, Theron AJ, Ramafi G, Feldman C. Effect of rolipram and dibutyryl cyclic AMP on resequestration of cytosolic calcium in FMLP-activated human neutrophils. Br J Pharmacol. 1998;124:547-55.

9. Sayeed MM. Exuberant $\mathrm{Ca} 2+$ signaling in neutrophils: a cause for concern. News Physiol Sci. 2000;15:130-5.
10. Souness JE, Griffin M, Maslen C, Ebsworth K, Scott LC, Pollock K, et al. Evidence that cyclic AMP phosphodiesterase inhibitors suppress TNF alpha generation from human monocytes by interacting with a 'low-affinity' phosphodiesterase 4 conformer. Br J Pharmacol. 1996; 118:649-58.

11. Hennessy VL, Hicks RE, Niewiarowski S, Edmunds LH, Colman RW. Function of human platelets during extracorporeal circulation. Am J Physiol. 1977;232:H622-8.

12. Rinder CS, Rinder HM, Johnson K, Smith M, Lee DL, Tracey J, et al. Role of C3 cleavage in monocyte activation during extracorporeal circulation. Circulation. 1999;100:553-8.

13. Wachtfogel YT, Kucich U, Hack CE, Gluszko P, Niewiarowski S, Colman RW, et al. Aprotinin inhibits the contact, neutrophil, and platelet activation systems during simulated extracorporeal perfusion. J Thorac Cardiovasc Surg. 1993;106:1-9.

14. Sato Y, Hogg JC, English D, van Eeden SF. Endothelin-1 changes polymorphonuclear leukocytes' deformability and CD11b expression and promotes their retention in the lung. Am J Respir Cell Mol Biol. 2000;23:404-10.

15. Holland BS, Copenhaver MD. An improved sequential rejective Bonferroni test procedure. Biometrics. 1987;42:417-23.

16. Pangburn MK, Muller Eberhard HJ. The alternative pathway of complement. Springer Semin Immunopathol. 1984;7:163-92.

17. Kolb WP, Morrow PR, Tamerius JD. Ba and Bb fragments of factor B activation: fragment production, biological activities, neoepitope expression and quantitation in clinical samples. Complement Inflamm. 1989;6:175-204.

18. Muller Eberhard HJ. The membrane attack complex of complement. Annu Rev Immunol. 1986;4:503-28.

19. Hogg JC, Doerschuk CM. Leukocyte traffic in the lung. Annu Rev Physiol. 1995;57:97-114.

20. Fink R, Al-Obaidi M, Grewal S, Winter M, Pepper J. Monocyte activation markers during cardiopulmonary bypass. Perfusion. 2003; 18:83-6.

21. Rinder CS, Rinder HM, Smith BR, Fitch JC, Smith MJ, Tracey JB, et al. Blockade of C5a and C5b-9 generation inhibits leukocyte and platelet activation during extracorporeal circulation. J Clin Invest. 1995;96:1564-72.

22. Finn A, Morgan BP, Rebuck N, Klein N, Rogers CA, Hibbs M, et al. Effects of inhibition of complement activation using recombinant soluble complement receptor 1 on neutrophil CD11b/CD18 and Lselectin expression and release of interleukin-8 and elastase in simulated cardiopulmonary bypass. J Thorac Cardiovasc Surg. 1996;111: 451-9.

23. Rinder CS, Rinder HM, Smith MJ, Tracey JB, Fitch J, Li L, et al. Selective blockade of membrane attack complex formation during simulated extracorporeal circulation inhibits platelet but not leukocyte activation dynamics of leukocyte-platelet adhesion in whole blood. J Thorac Cardiovasc Surg. 1999;118:460-6.

24. Le Deist F, Menasche P, Kucharski C, Bel A, Piwnica A, Bloch G. Hypothermia during cardiopulmonary bypass delays but does not prevent neutrophil-endothelial cell adhesion. A clinical study. Circulation. 1995;92(9 Suppl):II354-8.

25. Asimakopoulos G, Smith PL, Ratnatunga CP, Taylor KM. Lung injury and acute respiratory distress syndrome after cardiopulmonary bypass. Ann Thorac Surg. 1999;68:1107-15.

26. Tenner AJ. C1q interactions with cell surface receptors. Behring Inst Mitt. 1989(84):220-9.

27. Sato Y, Sato S, Yamamoto T, Ishikawa S, Onizuka M, Sakakibara Y. Phosphodiesterase type 4 inhibitor reduces the retention of polymorphonuclear leukocytes in the lung. Am J Physiol. 2002;282:L1376-81.

28. Sheth SB, Chaganti K, Bastepe M, Ajuria J, Brennan K, Biradavolu R, et al. Cyclic AMP phosphodiesterases in human lymphocytes. $\mathrm{Br} J$ Haematol. 1997;99:784-9.

29. Briggs WA, Wu Q, Orgul O, Choi M, Scheel PJ, Burdick J. Lymphocyte suppression by rolipram with other immunosuppressive drugs. J Clin Pharmacol. 1999;39:794-9. 